\title{
PESQUISA EMPÍRICA EM DIREITO: CLASSIFICAÇÃO DAS TESES E DISSERTAÇÕES DO PROGRAMA DE PÓS-GRADUAÇÃO DA UNIVERSIDADE DE SÃO PAULO (2015-2016)
}

\author{
Mariana Moron Saes Braga* \\ Rodrigo Maia de Oliveira**
}

\section{RESUMO}

A literatura tem apontado que a pesquisa empírica em direito ainda é incipiente no Brasil. As pesquisas são eminentemente bibliográficas e tem natureza predominantemente descritiva do ordenamento jurídico e dos conceitos dogmáticos nele estabelecidos. O objetivo deste artigo foi classificar as teses e dissertações defendidas no programa de pós-graduação em direito da Universidade de São Paulo entre 2015 e 2016. Foram utilizados dois critérios de classificação das teses e dissertações: segundo fontes de informação e natureza dos dados. Os resultados evidenciaram que as pesquisas produzidas no programa de pós-graduação pesquisado são em sua grande maioria bibliográficas e de natureza qualitativa.

Palavras-chave: ensino, direito, pesquisa empírica, produção científica, pós-graduação.

\section{EMPIRICAL RESEARCH IN LAW: CLASSIFICATION OF THESES AND DISSERTATIONS OF THE POSTGRADUATE LAW PROGRAMME OF THE UNIVERSITY OF SÃO PAULO (2015-2016)}

\begin{abstract}
The literature has pointed out that empirical research in law is still incipient in Brazil. Most researches are eminently bibliographical and descriptive. This study aimed to classify the theses and dissertations defended in the postgraduate law programme of the University of São Paulo in the years of 2015 and 2016. Two criteria were used to classify the academic works: according to sources of information and the nature of the data. The results showed that the theses and dissertations produced in the postgraduate law programme are mostly bibliographical and qualitative.
\end{abstract}

Keywords: teaching, law, empirical research, academic publications, postgraduate studies.

\footnotetext{
*Docente do Departamento de Sociologia e Antropologia da UNESP - Campus de Marília - Av. Hygino Muzzi Filho, 737, CEP 17.525-900, Marília, SP, Brasil.

** Doutor em Política Científica e Tecnológica pelo DPCT/UNICA
} 


\section{1- Introdução}

Em cada área há diferenças nas formas como os pesquisadores interagem para divulgar suas pesquisas e constituir suas relações acadêmicas. Cada área do conhecimento define, por razões históricas, assim como pela trajetória de institucionalização que cada uma delas teve, as suas próprias características para gerar uma determinada dinâmica de produção de conhecimento e, a partir daí, criar uma série de normas orientadas ao controle social da ciência.

Em tese defendida em 2011, Kunz objetivou analisar a dinâmica de produção de conhecimento na área de Direito no Brasil, ou seja, procurou compreender a dinâmica e as atitudes que levam os pesquisadores a tomar decisões variadas sobre sua agenda de pesquisa, sobre as fontes de informação necessárias para realizar seus trabalhos, assim como sobre os canais de divulgação de seus resultados de pesquisa. Ainda, analisou os meios ou canais preferidos para publicação e os critérios de citação da literatura pesquisada, tentando entender os fatores que levam a esses comportamentos distintos.

Uma das conclusões obtidas por Kunz (2011) é a de que a publicação em coautoria é minoritária na área, que tem uma tradição de pesquisa individual.

Em estudo anterior Braga e Oliveira (2016) também constataram que a publicação individual é majoritária em comparação à publicação em coautoria. De fato, os pesquisadores em Direito parecem cultivar o modo de trabalho isolado ou com pouca colaboração, que resulta em poucas publicações em coautoria.

Esse resultado confirma as observações prévias realizadas por Kunz (2011), fortalece o imaginário da pesquisa em Direito que remete à figura do doutrinador isolado e afasta a lógica coletiva e o trabalho empírico da pesquisa jurídica (FRAGALE FILHO; VERONESE, 2004).

O presente estudo também tem como ponto de partida outra constatação de Kunz (2011). Para a autora, há uma relação entre a predominância da autoria individual e o tipo de pesquisa realizada em direito.

Como já mencionado, uma de suas conclusões é de que estudantes de mestrado e doutorado na área tendem a publicar individualmente e não em coautoria com seus orientadores, sendo a coautoria uma prática bastante comum em várias áreas do conhecimento e estimulada pelos critérios de avaliação da CAPES. 
E segundo os pesquisadores que Kunz (2011) entrevistou, isso se deve à natureza da pesquisa em Direito, que é, predominantemente, bibliográfica. Neste caso, alegaram os entrevistados, que nem sempre é muito simples cooperar.

O objetivo do presente estudo foi o de classificar as teses e dissertações defendidas no programa de pós-graduação em direito da Universidade de São Paulo nos últimos dois anos (2015-2016), de acordo com dois critérios: segundo as fontes de informação e segundo a natureza dos dados.

Pretendeu-se verificar se em pesquisas mais recentes tem-se realizado outros tipos de pesquisa que não bibliográfica. A seguir, antes de apresentar o estudo propriamente dito, alguns apontamentos realizados pela literatura sobre a pesquisa em direito no Brasil e especificamente sobre a incipiente pesquisa empírica na área.

\section{2- Apontamentos sobre a pesquisa em direito no Brasil}

Assim como ocorre com a educação jurídica em geral, a literatura aponta uma série de questões consideradas problemáticas sobre a pesquisa em direito no Brasil. Para definir a situação da pesquisa em direito no Brasil, Nobre (2003, p. 146) utiliza a expressão relativo atraso quando a compara à pesquisa em ciências humanas no país.

Tanto se tem falado em crise no ensino do direito que uma entrevista recente com um dos precursores da questão, o professor e atual reitor da Universidade de Brasília, José Geraldo de Sousa Jr., foi intitulada "Basta de falar em crise", no sentido de que é chegado o momento de trabalhar e não mais de reclamar ${ }^{1}$. A novidade, portanto, não é a crise, nem o diagnóstico, mas a persistência do problema.

São muitos os trabalhos que, nas últimas décadas, procuraram mapear os problemas do ensino jurídico no Brasil. Nesses trabalhos, assim como nos debates travados em incontáveis seminários sobre o tema, é possível destacar ao menos dois aspectos centrais do diagnóstico.

De maneira geral, os trabalhos produzidos nesta área do conhecimento são tidos como formalistas, ou seja, eles têm natureza predominantemente descritiva do ordenamento jurídico e dos conceitos dogmáticos nele estabelecidos.

\footnotetext{
${ }^{1}$ Esta entrevista foi publicada na revista Getúlio, edição número 07, de janeiro de 2008. Pode ser encontrada no seguinte endereço eletrônico: http://bibliotecadigital.fgv.br.
} 
Como consequência disto, Oliveira (2012) argumenta que as pesquisas realizadas no campo jurídico no Brasil têm sido tradicionalmente mais teóricas do que empíricas. Segundo ela, há um paradigma fortemente estabelecido no direito, que concebe pesquisa jurídica como levantamento bibliográfico e análise crítica com confronto de teses, com o predomínio de pesquisas teóricas e dogmáticas.

Na verdade, no início da década de 90 Bastos (1991) já apontava para a predominância da pesquisa bibliográfica na área. Para ele, as faculdades de Direito, funcionam como mero centro de transmissão de conhecimento jurídico oficial e não, propriamente, como centros de produção do conhecimento jurídico. E ainda, segundo ele,

Neste sentido, a pesquisa nas faculdades de Direito está condicionada a reproduzir a "sabedoria" codificada e a conviver "respeitosamente" com as instituições que aplicam (e interpretam) o Direito positivo. O professor fala de códigos e o aluno aprende (quando aprende) em códigos. Esta razão, somada ao despreparo metodológico dos docentes (o conhecimento jurídico tradicional é um conhecimento dogmático e as suas referências de verdade são ideológicas e não metodológicas), explicam porque a pesquisa jurídica nas faculdades de Direito, na graduação (do que se poderia, inclusive, justificar pelo nível preliminar do aprendizado) e na Pós-Graduação, é exclusivamente bibliográfica, como exclusivamente bibliográfica e legalista é a jurisprudência de nossos próprios tribunais (BASTOS, 1991, p. 17).

Ainda segundo Oliveira (2012), o desprestígio da abordagem empírica nas pesquisas jurídicas se evidencia ainda mais quando se observa que a vasta maioria dos cursos de direito no país não possui tradição em pesquisa empírica.

$\mathrm{Na}$ pesquisa empírica, o pesquisador vai mais diretamente aos eventos e fatos, sem intermediação de outro observador, investigando as variáveis de seu objeto e tentando explicálas controladamente. Seus métodos são muitos, tais como questionários, entrevistas, estudos de caso, entre outros (ADEODATO, 1999).

Fragale Filho e Noronha (2012, p. 99) definem as pesquisas empíricas como pesquisas construídas a partir da observação do mundo, isto é, dados que podem ser tanto quantitativos quanto qualitativos.

Os referidos autores apontam que os estudos interdisciplinares e a incorporação de métodos empíricos ganharam corpo nos últimos anos e deixaram de ser completamente estranhos ao campo jurídico, embora os considerem incipientes no país.

Os pesquisadores que adotam o trabalho empírico como estratégia de abordagem enfrentam, de acordo com Fragale Filho e Noronha (2012, p. 98), três desafios: 
a) a necessidade de quebra de um paradigma fortemente estabelecido, que concebe a pesquisa jurídica como levantamento bibliográfico e a análise crítica como confronto de teses;

b) o estranhamento diante de métodos quantitativos e qualitativamente inapropriados para a análise de questões jurídicas; e

c) a difícil objetivação do problema examinado, quase sempre percebido de forma fluida e, portanto, dificilmente construído em torno de hipóteses aferíveis a partir de implicações observáveis.

Para Neri (2011) a pesquisa empírica em direito se propõe a dialogar com a produção científica de outras áreas do conhecimento, como a economia, a ciência política, a sociologia, abrindo-se a métodos e linguagens novas. Superada a ilusão de que os problemas de uma sociedade seguiriam a artificial taxonomia de saberes em que se organizam as ciências, nada mais recomendável do que enfrentá-los por meio de múltiplos olhares, para uma melhor apreensão do objeto analisado.

\section{3- Desenvolvimento do estudo}

Para a realização da pesquisa foi escolhido o programa de pós-graduação em direito da Universidade de São Paulo (USP). A Faculdade de Direito da USP foi criada em 1827, tendo sido incorporada à USP quando de sua fundação em 1934. É a mais antiga faculdade de Direito no Brasil, juntamente com a Faculdade de Direito de Olinda, e considerada por alguns rankings como a melhor no que diz respeito ao ensino jurídico.

Para essa seleção foi estabelecido o critério de que a universidade a ser escolhida tivesse um programa de pós-graduação consolidado e com pesquisas realizadas em diferentes áreas do direito. O programa de Pós-Graduação da Faculdade de Direito da USP foi criado pela Portaria GR nº 1211, de 25 de junho de 1970, do então Reitor da Universidade de São Paulo, o Prof. Dr. Miguel Reale. Os dados sobre o programa de Pós-Graduação e a lista das teses e dissertações defendidas nos últimos dois anos (2015 e 2016) foram obtidos na Plataforma Sucupira ${ }^{2}$.

\footnotetext{
${ }^{2}$ Os dados foram coletados em março de 2017. 
A referida plataforma é uma importante ferramenta para coletar informações, realizar análises e avaliações, sendo base de referência do Sistema Nacional de Pós-Graduação (SNPG). Ela disponibiliza em tempo real e com muito mais transparência as informações, processos e procedimentos que a Coordenação de Aperfeiçoamento de Pessoal de Nível Superior (CAPES) ${ }^{3}$ realiza no SNPG para toda a comunidade acadêmica. A escolha do nome da plataforma é uma homenagem ao professor Newton Sucupira, autor do Parecer no 977 de 1965. O documento conceituou, formatou e institucionalizou a pós-graduação brasileira nos moldes como é até os dias de hoje $\mathrm{e}^{4}$.

O programa de pós-graduação em direito da USP possui onze áreas de concentração ${ }^{5}$, conforme apresentado no quadro 01 abaixo.

Quadro 01: Áreas de concentração do Programa de Pós-graduação em Direito da USP.

\begin{tabular}{|l|c|}
\hline \multicolumn{1}{|c|}{ Áreas de concentração } & Data de início \\
\hline Direito Civil & $01 / 01 / 1971$ \\
\hline Direito Comercial & $01 / 01 / 1971$ \\
\hline Direito do Estado & $01 / 01 / 1971$ \\
\hline Direito do Trabalho e da Seguridade Social & $01 / 01 / 1971$ \\
\hline Direito Econômico e Financeiro & $01 / 01 / 1971$ \\
\hline Direito Internacional & $01 / 01 / 1971$ \\
\hline Direito Penal & $01 / 01 / 1971$ \\
\hline Direito Processual & $01 / 01 / 1971$ \\
\hline Direito Romano e Sistemas Jurídicos Contemporâneos & $30 / 05 / 2011$ \\
\hline Direitos Humanos & $01 / 01 / 2006$ \\
\hline Filosofia e Teoria Geral do Direito & $01 / 01 / 1971$ \\
\hline
\end{tabular}

Fonte: elaborado pelos autores com base em dados da Plataforma Sucupira, 2017.

Na Plataforma Sucupira há um menu intitulado trabalhos de conclusão. Este menu destina-se ao registro dos trabalhos de conclusão defendidos e aprovados nos cursos de mestrado acadêmico, mestrado profissional e de doutorado dos programas de pós-graduação durante o ano base. Além de dados cadastrais e de catalogação bibliográfica, é requerido um conjunto extenso de informações complementares, cujo objetivo é relacionar os trabalhos de conclusão às linhas de pesquisas e projetos e aos orientadores do programa, registrar seus

\footnotetext{
${ }^{3}$ A CAPES é uma fundação pública vinculada ao Ministério da Educação (MEC) do Brasil que atua na expansão e consolidação da pós-graduação stricto sensu (mestrado e doutorado) em todos os estados do país.

${ }^{4} \mathrm{http} / / /$ www.capes.gov.br/avaliacao/plataforma-sucupira.

${ }^{5}$ A página virtual da universidade menciona apenas dez áreas de concentração, mas conforme dados inseridos e atualizados pelo próprio programa de pós-graduação na Plataforma Sucupira são onze as áreas de concentração. Acesso em: 16/03/2017.
} 
financiadores e a intenção de trabalho futuro dos autores, após a conclusão de seus cursos de pós-graduação.

Nesse menu de trabalho de conclusão disponível na Plataforma Sucupira foram identificadas as teses e dissertações defendidas nos anos de 2015 e 2016. Ao todo foram identificados 626 trabalhos de conclusão, sendo 406 dissertações e 220 teses. Esses números foram organizados no quadro 02 a seguir.

Quadro 02: Trabalhos defendidos no programa de pós-graduação em Direito da USP.

\begin{tabular}{|c|c|c|c|}
\hline Trabalho de conclusão & $\mathbf{2 0 1 5}$ & $\mathbf{2 0 1 6}$ & Total \\
\hline Dissertação & 179 & 227 & 406 \\
\hline Tese & 100 & 120 & 220 \\
\hline Total & $\mathbf{2 7 9}$ & $\mathbf{3 4 7}$ & $\mathbf{6 2 6}$ \\
\hline
\end{tabular}

Fonte: elaboração própria.

Neste ponto vale uma primeira observação importante. Após o levantamento da lista de trabalhos de conclusão defendidos anualmente no programa pesquisado, procedeu-se à busca de cada dissertação e tese, de modo a permitir a classificação e análise proposta no objetivo deste artigo. Os trabalhos foram buscados no Portal da Biblioteca Digital de Teses e Dissertações da Universidade de São Paulo ${ }^{6}$ e na própria Plataforma Sucupira.

Muito embora as bases de dados listassem a existência de 626 trabalhos de conclusão defendidos entre 2015 e 2016, apenas uma parcela desse total estava disponível para consulta total ou parcial. De fato, do total de 626 teses e dissertações listadas, foram encontrados apenas 359 trabalhos de conclusão, que representam cerca de 57\% do total de teses e dissertações defendidas no período (quadro 03).

Quadro 03: Trabalhos de conclusão disponibilizados pelos autores para consulta.

\begin{tabular}{|c|c|c|c|}
\hline Trabalho de conclusão & $\mathbf{2 0 1 5}$ & $\mathbf{2 0 1 6}$ & Total \\
\hline Dissertação & 157 & 84 & 241 \\
\hline Tese & 74 & 44 & 118 \\
\hline Total & $\mathbf{2 3 1}$ & $\mathbf{1 2 8}$ & $\mathbf{3 5 9}$ \\
\hline
\end{tabular}

Fonte: elaboração própria.

Infelizmente, não é possível saber ao certo quais razões explicariam significativa ausência dos documentos nas referidas bases de dados. Algumas hipóteses surgem como sendo as causas mais prováveis, embora mereçam verificação futura, a saber: problemas de

\footnotetext{
${ }^{6} \mathrm{~A}$ biblioteca digital pode ser acessada no seguinte endereço eletrônico: http://www.teses.usp.br/ 
processamento das informações nas bases de dados, problemas administrativos do programa de pós-graduação em direito da USP que por alguma razão deixou de inserir as informações na base de dados no prazo previsto, decisão consciente dos autores de restringir o acesso ao documento por questões de interesse autoral ou editorial, dentre outras.

No sentido de oferecer melhor caracterização desse conjunto de 359 trabalhos de conclusão encontrados, os mesmos foram classificados segundo a sua área de concentração, conforme apresentado anteriormente. $\mathrm{O}$ gráfico 01 a seguir apresenta a distribuição do número de trabalhos por cada area de concentração.

Gráfico 01: Trabalhos de conclusão segundo fontes de informação.

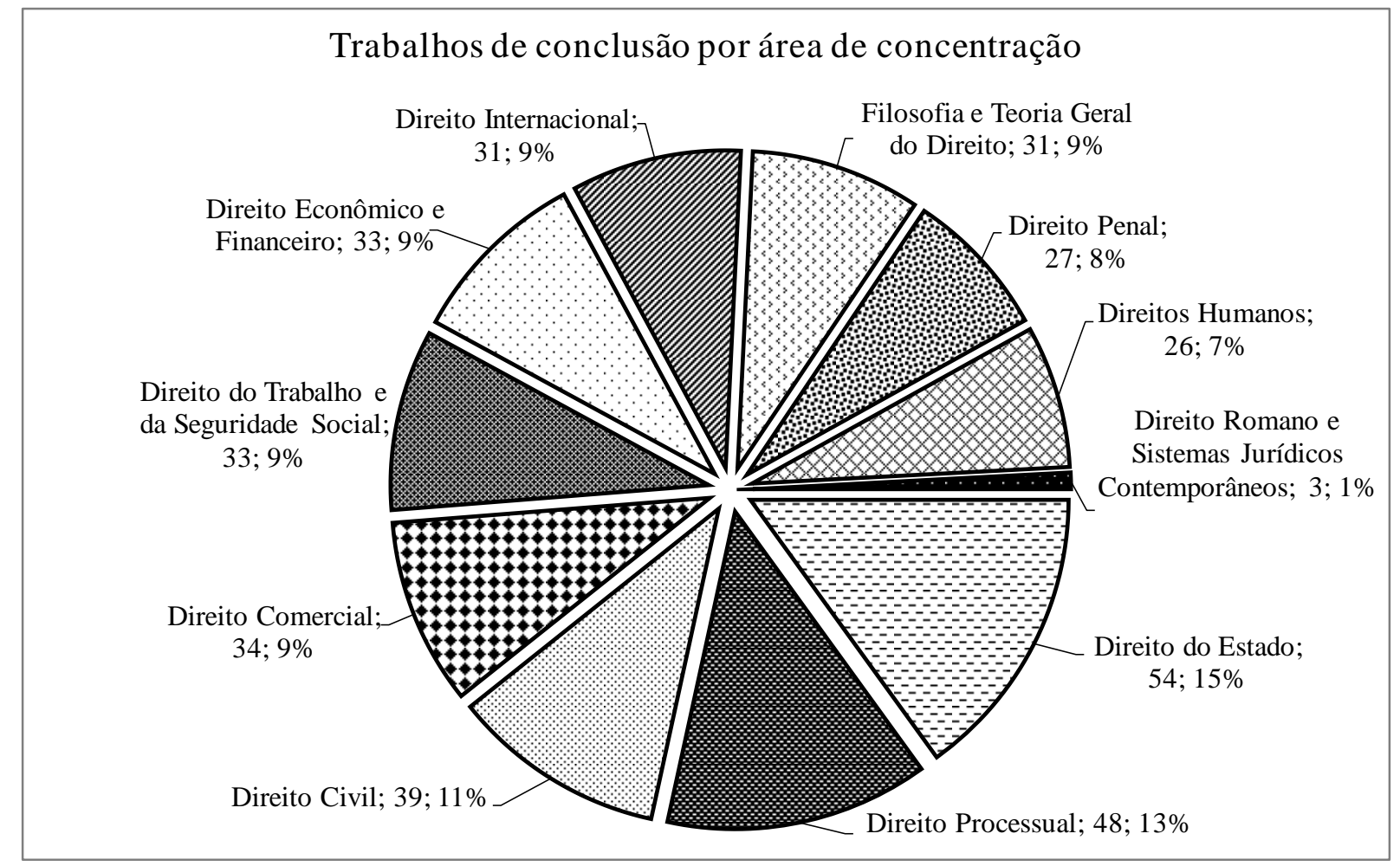

Fonte: elaboração própria.

Vale observar que, exceto no caso da área de Direito Romano e Sistemas Jurídicos Contemporâneos, cujo número de trabalhos encontrados foi de apenas 3 , as demais áreas de 
concentração apresentaram distribuição relativamente equivalente entre as teses e dissertações avaliadas. Acredita-se que o baixo número de trabalhos na área de Direito Romano e Sistemas Jurídicos Contemporâneos reflete o fato da mesma ter sido criada em período bem mais recente (2011) em comparação às demais. Nesse sentido, também merece destaque o número de trabalhos defendidos na área de Direitos Humanos que, embora tenha sido criada em 2006, apresenta número de trabalhos no mesmo nível de áreas tradicionais tal como o Direito Penal.

Voltando ao assunto da integridade das teses e dissertações encontradas, uma segunda observação merece destaque. De fato, ao realizar as buscas pelas teses e dissertações, percebeuse que dos 359 documentos disponibilizados pelos autores, 219 (61\%) encontravam-se na forma completa e os outros 140 (39\%) encontravam-se em formato resumido, ou seja, apenas parte do trabalho podia ser lida (em geral, continham apenas resumo, sumário, introdução e conclusão) ${ }^{7}$.

A esse respeito, duas regras institucionais ajudam a disciplinar o tema da publicação dos resultados das pesquisas produzidas na forma de dissertações e teses. A primeira delas se refere à Portaria no 013 da Coordenação de Aperfeiçoamento de Pessoal de Nível Superior (CAPES) que, em 2006, instituiu a divulgação digital das teses e dissertações produzidas pelos programas de doutorado e mestrado reconhecidos. A outra regra é a Resolução CoPGr $\mathrm{n}^{\circ} 5401$ de 2007 da Pró Reitoria de Pós-Graduação da USP $^{8}$ que regulamentou a disponibilização de dissertações e teses no Portal da USP.

Em 2007, o presidente da CAPES, professor Jorge Guimarães concedeu entrevista (JORNAL DA USP, 2007) explicitando o objetivo da portaria que tornou obrigatória a publicação de teses e dissertações reconhecidas pela CAPES:

A publicação das teses é uma exigência de todos os comitês de
avaliação da Capes, existente desde 1976, quando tal avaliação foi
estabelecida. A pergunta em questão parece se referir à divulgação no
Portal de Domínio Público do MEC, que inclui o Banco de Teses e mais
de 30 mil textos diversos. A experiência do envio das teses à Capes, a
quem cabe alimentar o Portal do MEC, é parte de um instrumento de
coleta de dados chamado Cadastro de Discentes, criado em 2005. Esse
cadastro é um instrumento gerencial fundamental para a agência, que
auxilia na definição da política de concessão de bolsas na medida em
que proporciona uma fotografia em tempo real, atualizada, da pós-
graduação. Serve também como ferramenta de apoio ao preenchimento

\footnotetext{
${ }^{7}$ Os autores entenderam que, embora uma parcela das teses e dissertações estivessem incompletas, isso não inviabilizava a realização da classificação pretendida pois a metodologia utilizada é apresentada, na maioria dos casos, tanto no resumo quanto na introdução das pesquisas.

${ }^{8}$ A resolução pode ser acessada no seguinte endereço eletrônico: http://www.leginf.usp.br/?resolucao=resolucaocopgr-5401-de-17-de-abril-de-2007.
} 
da Coleta de Dados anual da Capes, aplicativo essencial para a avaliação dos cursos de pós-graduação do país. Além disso, é uma base estatística que apresenta o perfil do estudante de mestrado e doutorado até então inexistente, atualizado diariamente. O Banco de Teses é mais um elemento de garantia da originalidade das teses. A produção científica discente é um relevante indicador da qualidade dos programas de mestrado e doutorado, não aferível apenas através da publicação seletiva nos periódicos especializados.

O então presidente da CAPES também foi questionado se a publicação obrigatória pode acabar com o ineditismo da obra, o que causaria uma perda de interesse para publicação editorial. De acordo com Guimaraes (JORNAL DA USP, 2007):

Quanto à possível perda de interesse na publicação, deve-se considerar
que a tese que não gera publicação final não contribui para o bom
conceito do curso e, portanto, a publicação é uma consequência natural
do trabalho desenvolvido no curso. O argumento só pode ser válido para
o caso de gerar uma publicação na forma de livro. Mas, de novo, essa
condição está preservada mediante a informação de que um livro
original está em fase de redação ou publicação. Quem lê ou toma
conhecimento de uma tese que não está divulgada? Qual o autor que
não busca divulgar seu trabalho? No caso das publicações em revistas,
esse argumento inexiste.

Prevendo os casos em que o autor necessite manter sua tese em sigilo, a portaria da CAPES prevê, no artigo $2^{\circ}$, o eventual não depósito da obra, "motivada pela proteção ao sigilo industrial ou ético". Assim, os trabalhos inclusos nesses casos estariam livres da obrigatoriedade, bastando para tal, segundo a CAPES, apenas a indicação do motivo no formulário de inscrição da tese.

$\mathrm{Na}$ entrevista mencionada acima, o professor Jorge Guimarães explica que é simples o procedimento para a não publicização da obra: Não há necessidade de interposição de recurso. A coordenação do programa de pós-graduação simplesmente marca, no aplicativo de preenchimento, o trabalho como "não divulgável" e justifica sua não inclusão de forma a não haver sua disponibilização (JORNAL DA USP, 2007).

Conforme mencionado anteriormente foram encontradas para consulta praticamente apenas metade das teses e dissertações elaboradas nos anos pesquisados. Uma hipótese provável para uma quantidade tão pequena talvez seja o fato de que o artigo $2^{\circ}$ não explicita claramente que situações permitiriam que a tese não fosse publicada. Com isto, os autores podem estar se valendo desta imprecisão e não permitindo a divulgação da obra.

De fato, a Portaria $\mathrm{n}^{\circ} 013$ da CAPES dividiu opiniões de alunos, professores e editores. Considerando que há uma série de normas jurídicas que protegem os autores de diversas 
violações como o plágio, por exemplo, pondera-se que de fato o valor que tem embasado opiniões contrárias à vigência da portaria é o valor econômico da obra.

Ainda no que se refere à polêmica provocada pela Portaria $n^{\circ} 013$ da CAPES, Fragale Filho (2008, p. 30) narra o questionamento de um aluno e sua resposta:

\begin{abstract}
"Professor, isso é inconstitucional". E logo respondi: "Como? Onde? Ao que você está se referindo?". E os comentários que acompanho em nossa área têm sido no sentido de que "isso é um desrespeito ao direito do autor, isso tolhe a capacidade de publicação posterior porque o editor não vai ter interesse em uma obra que está em domínio público", sem perceber que, na verdade, o que temos aqui é uma lógica de transparência e verificação de produção científica pela comunidade. Não estamos trabalhando na produção de um livro, e sim na criação de um produto acadêmico que deve ser exposto aos seus pares.
\end{abstract}

Especificamente no caso da regra interna da USP, há previsão clara no seu artigo $2^{\circ}$ de que os alunos que tiverem interesse em resguardar patentes, direitos autorais e outros direitos, relativos aos seus trabalhos, podem solicitar à Comissão de Pós-Graduação (CPG) de sua unidade, mediante requerimento devidamente justificado, a não disponibilização de versão integral de sua dissertação ou tese no Portal da USP. Após parecer de um dos seus membros a referida comissão julga se o aluno deverá entregar a versão eletrônica completa de sua dissertação ou tese, acompanhada de uma outra, simplificada, que contenha apenas o título, o resumo, a introdução, a conclusão e a bibliografia do trabalho. Essa condição de "publicação resumida" na Biblioteca Digital da USP perdura pelo prazo de 02 anos, podendo tal prazo ser renovado por mais 02 anos. Após esse período, de no máximo 04 anos, a dissertação ou tese passa a ser disponibilizada integralmente na Biblioteca Digital da USP.

Enfim, para atingir o objetivo pretendido neste trabalho, após identificadas as monografias, realizou-se a leitura e classificação de cada uma delas. Em seguida foi realizada uma análise quantitativa e outra qualitativa dos dados encontrados.

Para a análise qualitativa foram utilizados dois dos critérios da classificação das pesquisas oferecida por Gonsalves $(2003)^{9}$ :

- Tipos de pesquisas segundo as fontes de informação; e

- Tipos de pesquisas segundo a natureza dos dados.

\footnotetext{
${ }^{9}$ Pode-se classificar as pesquisas segundo diferentes critérios. Gil (2010) por exemplo, apresenta apenas quatro classificações: segundo a área do conhecimento, segundo sua finalidade, uma com base nos objetivos mais gerais e outra com base nos métodos empregados.
} 
O quadro 04 a seguir apresenta os tipos de pesquisa conforme a classificação elaborada por Gonsalves (2003):

Quadro 04: Classificação das pesquisas elaboradas por Gonsalves (2003).

\begin{tabular}{|l|c|}
\hline $\begin{array}{c}\text { Tipos de pesquisas segundo as } \\
\text { fontes de informação }\end{array}$ & $\begin{array}{c}\text { Tipos de pesquisas segundo a } \\
\text { natureza dos dados }\end{array}$ \\
\hline - Campo & $\bullet$ Quantitativa \\
- Experimental (Laboratório) & $\bullet$ Qualitativa \\
- Bibliográfica & \\
- Documental & \\
\hline
\end{tabular}

Fonte: adaptada de Gonsalves (2003).

Quanto às fontes de informação, Gonsalves (2003) contempla os seguintes tipos de pesquisa: campo, laboratório, bibliográfica e documental. Nessa classificação, os tipos de pesquisa são agrupados segundo a natureza das fontes utilizadas.

A pesquisa de campo é o tipo de pesquisa que pretende buscar a informação diretamente com a população pesquisada. É aquela que exige do pesquisador um encontro mais direto. Nesse caso, o pesquisador precisa ir ao espaço onde o fenômeno ocorre ou ocorreu e reunir um conjunto de informações a serem documentadas (GONSALVES, 2003).

A investigação experimental é aquela que se refere a um fenômeno que é reproduzido de forma controlada, submetendo os fatos à verificação, buscando a partir daí evidenciar as relações entre os fatos e as teorias. A pesquisa experimental adota o critério de manipulação de uma ou mais variáveis independentes sob adequado controle, a fim de observar e interpretar as reações e as modificações ocorridas no objeto de pesquisa (GIL, 2010).

Para Gil (2010), as pesquisas realizadas em laboratório, ou seja, os experimentos, representam o melhor exemplo de pesquisa cientifica. Essencialmente, consistem em determinar um objeto de estudo, selecionar as variáveis que seriam capazes de influenciá-lo, definir as formas de controle e de observação dos efeitos que a variável produz no objeto.

Quando os objetos de estudo são entidades físicas, tais como porções de líquidos, não se identificam grandes limitações quanto à possibilidade de experimentação. Quando, porém, se trata de experimentar com objetos sociais, ou seja, com pessoas, grupos ou instituições, as limitações tornam-se bastante evidente. Considerações éticas e humanas impedem que a experimentação se faça eficientemente nas ciências humanas, razão pela qual os procedimentos experimentais se mostram adequados apenas a um número reduzido de situações. 
A pesquisa bibliográfica é desenvolvida a partir de material já elaborado, constituído principalmente de livros e artigos científicos. Embora em quase todos os estudos seja exigido algum tipo de trabalho desta natureza, há pesquisas desenvolvidas exclusivamente a partir de fontes bibliográficas (CERVO; BERVIAN, 1983).

Embora se assemelhe à pesquisa bibliográfica, a pesquisa documental não levanta material editado: livros, periódicos, etc. A natureza das fontes é a diferença essencial entre ambas. A pesquisa documental vale-se de materiais que não receberam ainda um tratamento analítico, ou que ainda podem ser reelaborados de acordo com os objetivos da pesquisa. Podemse identificar pesquisas elaboradas a partir de fontes documentais as mais diversas, tais como: correspondência pessoal, documentos cartoriais, epitáfios, relatórios, propostas, avisos, registros de batismo, etc. (MARTINS; THEÓPHILO, 2007; GIL, 2010).

Neste momento, um esclarecimento importante deve ser feito em relação a análise dos dados. As pesquisas jurídicas, em sua maioria, poderiam ser consideradas documentais. Isto se deve ao fato de que o objeto do estudo do direito é quase sempre a norma jurídica. Em sua maioria, as pesquisas da área envolvem algum tipo de análise legislativa.

Entretanto, neste estudo só foram consideradas documentais as pesquisas que de fato utilizaram as normas jurídicas existentes como documento de investigação. Portanto, foram considerados bibliográficos os trabalhos que têm natureza predominantemente descritiva do ordenamento jurídico e dos conceitos dogmáticos nele estabelecidos.

Para Mattos e Pereira Neto (2008), a produção acadêmica em direito assume o sistema jurídico como sendo fechado e estático, sem incorporar elementos explicativos das condições (dinâmicas) de operação do direito ou elementos normativos no sentido de propor alternativas de desenho das instituições relacionadas à operação do direito. Ainda segundo os autores, como exemplo do formalismo jurídico encontram-se três tipos de trabalhos:

a) Trabalhos de reconstrução doutrinária sobre conceitos descritivos de normas e sistemas normativos (em geral com a apresentação do posicionamento de diversos autores sobre cada conceito);

b) Descrição legislativa (apresentação do quadro normativo formado pelas constituições federal e estaduais, leis e regulamentos); e

c) Descrição de julgados (decisões judiciais ou administrativas que afirmam posicionamentos sobre a aplicação do quadro normativo). 
Embora a norma jurídica e as decisões judiciais possam ser considerados documentos ${ }^{10}$, os tipos de pesquisa descritos acima não podem ser considerados documentais.

Para Sá-Silva et al. (2009), quando um pesquisador utiliza documentos objetivando extrair dele informações, ele o faz investigando, examinando, usando técnicas apropriadas para seu manuseio e análise; segue etapas e procedimentos; organiza informações a serem categorizadas e posteriormente analisadas; por fim, elabora sínteses, ou seja, na realidade, as ações dos investigadores, cujos objetos são documentos, estão impregnadas de aspectos metodológicos, técnicos e analíticos.

Como exemplo de uma pesquisa em que a legislação foi utilizada de fato como documento tem-se a tese de Cruz (2016). Para aferir o impacto da medida provisória nos âmbitos de atuação da Presidência da República, do Congresso Nacional e do Supremo Tribunal Federal o pesquisador analisa todo o universo de medidas provisórias editadas após a Emenda Constitucional 32. Desta forma, por meio de análise documental, o pesquisador propôs-se a produzir/reelaborar conhecimentos e criar novas formas de compreender o fenômeno estudado.

Quanto à natureza dos dados, as pesquisas quantitativas são aquelas em que os dados e as evidências coletadas podem ser quantificados, mensurados. Os dados são filtrados, organizados e tabulados, enfim, preparados para serem submetidos a técnicas e/ou testes estatísticos. A análise e interpretação se orientam através do entendimento e conceituação de técnicas e métodos estatísticos. No entanto, em função de propósitos de certas pesquisas e abordagens metodológicas empreendidas, o tipo das informações, dados e evidências obtidas não são passíveis de mensuração. Pedem descrições, compreensões, interpretações e análise de informações, fatos, ocorrências, evidências que não são expressas por dados e números. Têmse aí as características de uma pesquisa qualitativa (MARTINS; THEÓPHILO, 2007).

Para Gustin et al. (2012), em qualquer área de estudo, não deve existir uma separação estanque entre enfoques qualitativo e quantitativo, mas sim uma complementaridade entre essas duas formas de análises. É possível realizar uma pesquisa prioritariamente quantitativa, mas isso não significa que ela não deva ser considerada também qualitativa, vez que os números não falam por si, dependem de uma análise valorativa.

\footnotetext{
${ }^{10}$ Segundo Appolinário (2009) documento é qualquer suporte que contenha informação registrada, formando uma unidade, que possa servir para consulta, estudo ou prova. Incluem-se nesse universo os impressos, os manuscritos, os registros audiovisuais e sonoros, as imagens, entre outros.
} 
Diante disto é preciso esclarecer algo em relação à análise dos dados. As pesquisas que poderiam ser consideradas pesquisas mistas com enfoque qualitativo e quantitativo foram classificadas como quantitativas. O objetivo do presente estudo foi o de verificar se estão sendo produzidas outros tipos de pesquisa que não as que utilizam apenas dados qualitativos. Dessa forma, aquelas pesquisas que levantaram dados quantitativos, ainda que também tenham realizado análises qualitativas, foram classificadas como quantitativas. Feita desta forma, a análise evidencia qual a quantidade de pesquisas que deram outro tratamento aos dados coletados, transformando-os em números ou letras passíveis de contagem e tabulação.

Tendo como base os critérios de classificação dos tipos de pesquisa expostos, procedeu-se a leitura, classificação e tabulação dos dados cujos resultados encontrados são apresentados a seguir.

\section{4- $\quad$ Resultados e discussões}

Nesta parte concentram-se as informações encontradas sobre os tipos de pesquisas desenvolvidas pelo corpo discente do programa de pós-graduação em direito da Universidade de São Paulo em 2015 e 2016. Os resultados se subdividem conforme os critérios analisados, ou seja, segundo as fontes de informação e a natureza dos dados.

\section{1- Classificação das pesquisas segundo as fontes de informação}

Os dados sobre a fonte de informação das pesquisas foram agrupados em quatro categorias: pesquisa bibliográfica, pesquisa documental, pesquisa de campos e pesquisa experimental. O quadro 05 a seguir apresenta o resultado do número de trabalhos para cada tipo de pesquisa segundo a sua fonte de informação.

Quadro 05: Trabalhos de conclusão segundo suas fontes de informação.

\begin{tabular}{|c|c|c|c|c|c|}
\hline Ano & $\begin{array}{l}\text { Trabalho de } \\
\text { conclusão }\end{array}$ & $\begin{array}{c}\text { Pesquisa } \\
\text { Bibliográfica }\end{array}$ & \begin{tabular}{|c|} 
Pesquisa \\
Documental
\end{tabular} & \begin{tabular}{|c|}
$\begin{array}{c}\text { Pesquisa de } \\
\text { Campo }\end{array}$ \\
\end{tabular} & $\begin{array}{c}\text { Pesquisa } \\
\text { Experimental }\end{array}$ \\
\hline 2015 & Dissertação & 119 & 32 & 6 & 0 \\
\hline 2015 & Tese & 54 & 17 & 3 & 0 \\
\hline 2016 & Dissertação & 58 & 20 & 5 & 0 \\
\hline 2016 & Tese & 29 & 13 & 3 & 0 \\
\hline \multicolumn{2}{|c|}{$\begin{array}{c}\text { Total } \\
\text { (Percentual) }\end{array}$} & $\begin{array}{c}260 \\
(72,4 \%)\end{array}$ & $\begin{array}{c}\mathbf{8 2} \\
(22,8 \%)\end{array}$ & $\begin{array}{c}17 \\
(4,7 \%) \\
\end{array}$ & $\begin{array}{c}0 \\
(0,0 \%)\end{array}$ \\
\hline
\end{tabular}


Fonte: elaboração própria.

O resultado mais evidente, a partir da elaboração do quadro 05, é que 72,4\% das teses e dissertações disponíveis e que foram avaliadas para o período de 2015 e 2016 são aquelas que têm como fonte de informação a pesquisa bibliográfica. A segunda fonte de informação mais usada foi a pesquisa documental, que representa apenas $22,8 \%$ do total de trabalhos de conclusão avaliados. Na sequência, a terceira fonte de informação usada foi a pesquisa de campo que somou apenas 17 trabalhos de conclusão dos 359 avaliados, representando 4,7 \% do total. Pode-se considerar esta porcentagem pequena se levarmos em conta a abundância de fontes empíricas que podem ser utilizadas em pesquisas em direito. Nenhum dos trabalhos de conclusão avaliados usou a pesquisa experimental como fonte de informação.

O gráfico 02 abaixo permite visualizar com facilidade a distribuição dos trabalhos de conclusão avaliados nas quatro categorias de análise que congregam as fontes de informação.

Gráfico 02: Trabalhos de conclusão segundo fontes de informação.

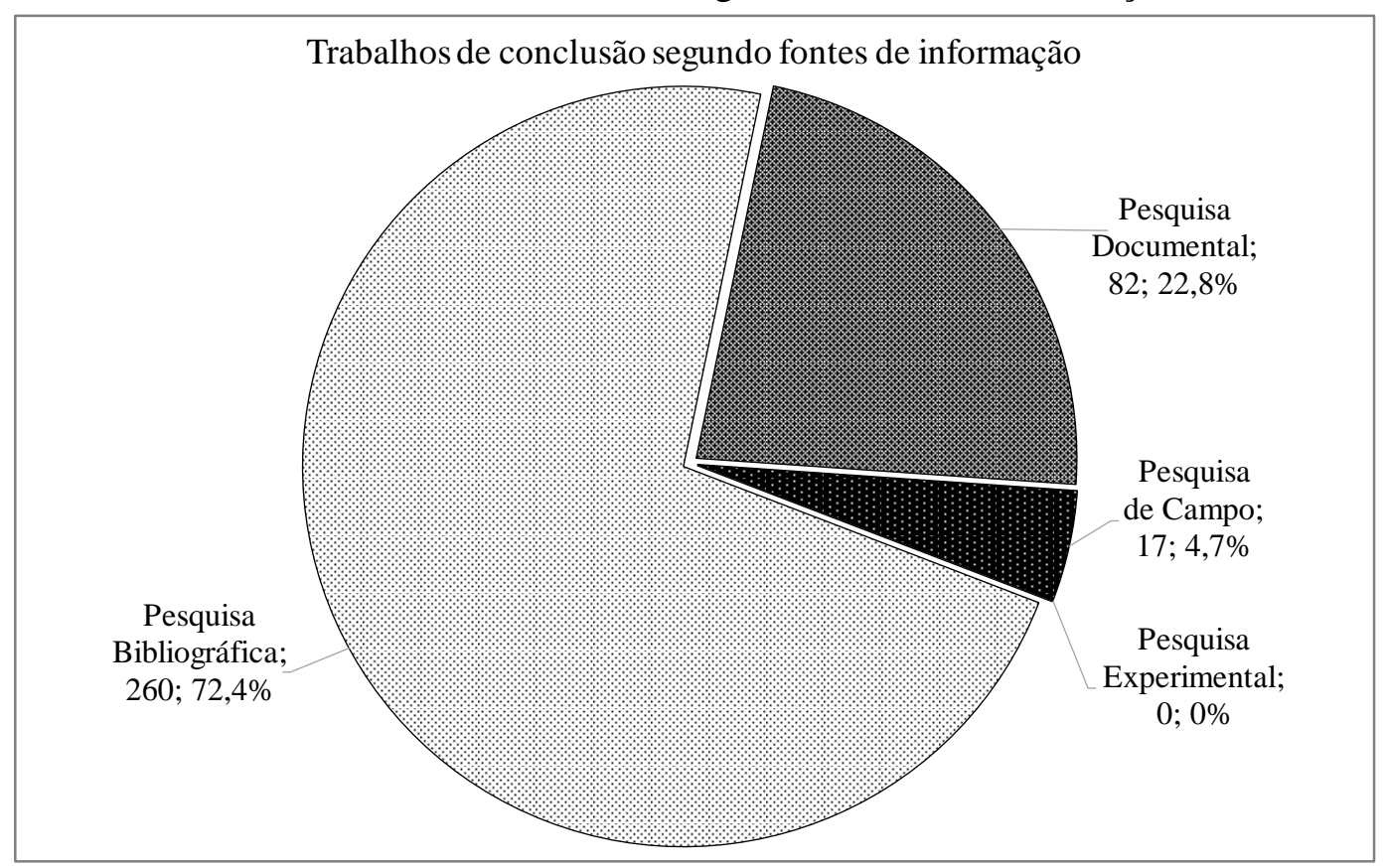

Fonte: elaboração própria.

Os dados coletados permitiram uma outra análise que está diretamente relacionada ao objetivo pretendido. Como já mencionado, de um total de 359 trabalhos de conclusão de curso analisados, apenas 17 podem ser classificados como pesquisa de campo, de acordo com a fonte 
de informação. Com base nesse resultado, procedeu-se uma nova análise, levando-se em consideração as áreas de concentração em que cada trabalho foi conduzido.

De fato, buscou-se verificar se dentre os trabalhos de conclusão que foram classificados como pesquisa de campo predominavam trabalhos de uma ou mais áreas de concentração. O gráfico 03 a seguir apresenta o total de trabalhos de campo distribuídos pelas áreas de concentração em que estão inseridos.

Gráfico 03: Trabalhos empíricos (de campo) por área de concentração.

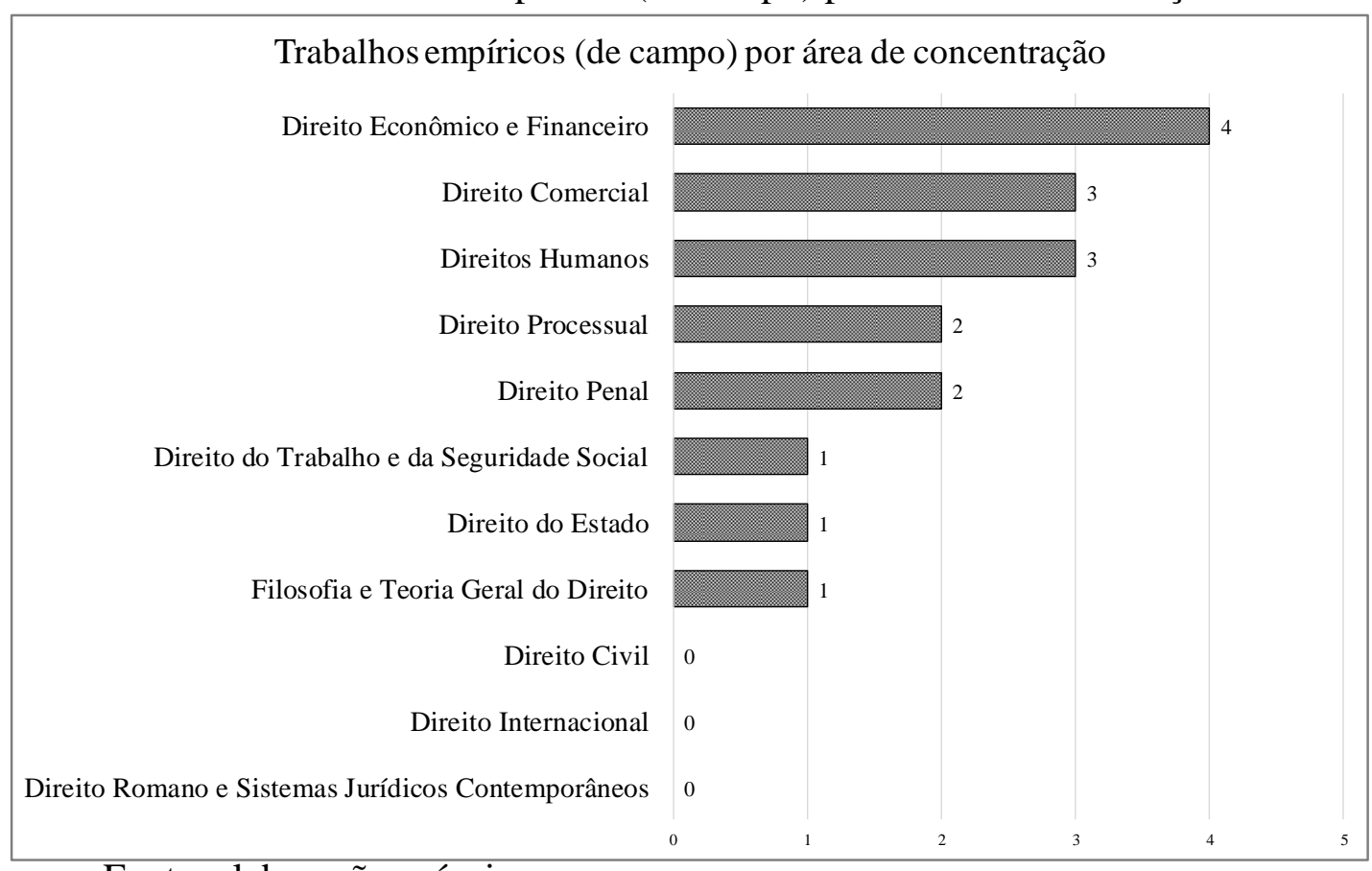

Fonte: elaboração própria.

O gráfico 03 permite observar que a pequena porcentagem de trabalhos de campo encontrada, considerando a totalidade das pesquisas classificadas, se distribui de maneira proporcional entre as áreas de concentração existentes no programa de pós-graduação da USP. Isso sugere que a ausência de pesquisa empírica traduz um comportamento generalizado entre as áreas de concentração do direito. Assim, não há uma área que, por possuir alguma característica específica, tenha se destacado de modo a produzir um maior número de pesquisas de campo e, consequentemente, utilize outros instrumentos de coleta de dados, tais como questionários e entrevistas, por exemplo.

\section{2- Classificação das pesquisas segundo a natureza dos dados}


Conforme mencionado anteriormente, os trabalhos de conclusão do programa de pósgraduação em direito da USP dos últimos dois anos também foram classificados segundo a natureza dos dados avaliados. Conforme evidencia o quadro 06 a seguir, 94,2\% das pesquisas analisadas são de enfoque qualitativo e apenas 5,8\% de enfoque quantitativo. O gráfico 04 ajuda a visualizar essa enorme disparidade entre as pesquisas quantitativas e qualitativas em direito.

Quadro 06: Trabalho de conclusão segundo a natureza dos dados.

\begin{tabular}{|c|c|c|c|}
\hline Ano & Trabalho de conclusão & Pesquisa Qualitativa & Pesquisa Quantitativa \\
\hline 2015 & Dissertação & 149 & 8 \\
\hline 2015 & Tese & 68 & 6 \\
\hline 2016 & Dissertação & 79 & 4 \\
\hline 2016 & Tese & 42 & 3 \\
\hline \multicolumn{2}{|r|}{ Totais (Percentual) } & $\mathbf{3 3 8}(\mathbf{9 4 , 2 \% )}$ & $\mathbf{2 1}(\mathbf{5 , 8 \%})$ \\
\hline
\end{tabular}

Fonte: elaboração própria.

Gráfico 04: Trabalhos de conclusão segundo a natureza dos dados.

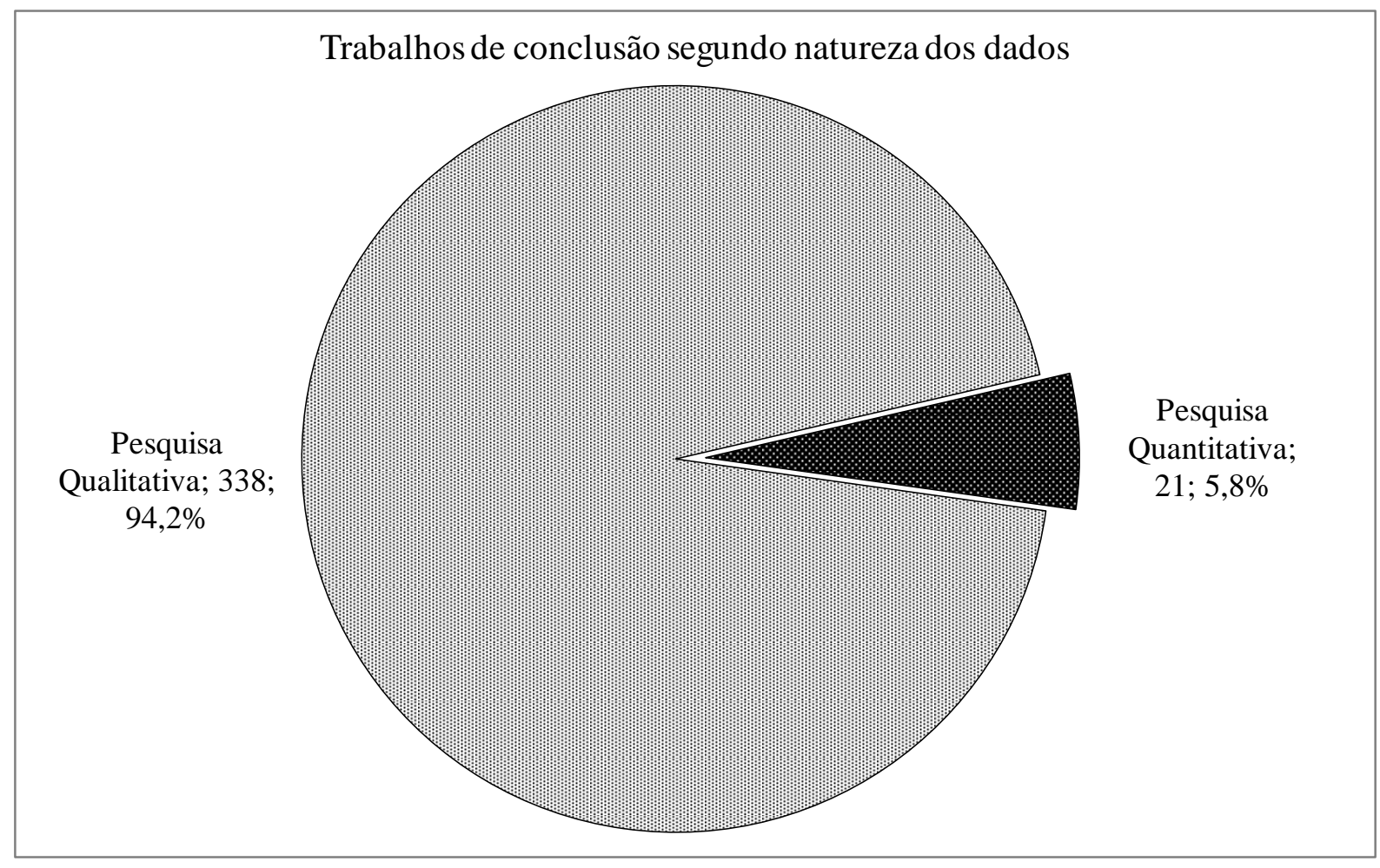

Fonte: elaboração própria. 


\section{5- Considerações finais}

A primeira consideração a ser feita é de que o artigo alcançou o objetivo proposto, ou seja, foram avaliados e classificados os 359 trabalhos de conclusão desenvolvidos nos últimos dois anos (2015 e 2016) no programa de pós-graduação em direito da USP e disponibilizados pelos autores, tendo como referência os critérios das fontes de informação e natureza dos dados conforme definidos por Gonsalves (2011).

O percurso metodológico evidenciou um aspecto importante. Os autores têm disponibilizado para consulta em torno de metade dos trabalhos produzidos pelo programa de pós-graduação em direito da USP. As causas desse reduzido número de trabalhos disponibilizados ainda não são claras, mas há a suspeita de que podem haver problemas de caráter administrativo, relacionados à inserção dos dados e documentos nas bases consultadas, e de caráter autoral, relacionados à interesses editoriais. De qualquer modo, parece haver alguma lógica estranha aos valores relacionados à disseminação do conhecimento. Trabalhos futuros podem ajudar a esclarecer este aspecto observado durante o levantamento de dados desta pesquisa.

Os resultados observados explicitam a significativa predominância dos trabalhos de natureza bibliográfica e de enfoque qualitativo, em consonância com vários apontamentos da literatura acadêmica sobre o tema (BASTOS, 1991; KUNZ, 2011; OLIVEIRA, 2012; FRAGALE FILHO E NORONHA, 2012).

Considerando que os trabalhos de conclusão de curso desenvolvidos nos programa de pós-graduação em direito da USP congregam a produção acadêmica jurídica nacional de uma das melhores universidades do país, os resultados deste artigo ajudam a ratificar a tese de que a pesquisa teórica predomina sobre a pesquisa empírica em direito no Brasil, com destaque para o levantamento bibliográfico como principal forma de conduzir a pesquisa (OLIVEIRA, 2012).

De fato, este artigo apresenta a enorme discrepância existente entre a pesquisa teórica e a pesquisa empírica em direito no Brasil. O fazer científico na atualidade requer uma multiplicidade de enfoques metodológicos e uma variedade de técnicas e de procedimentos. Isto também se aplica à atual produção do conhecimento jurídico, a despeito do que se pensa sobre a Ciência do Direito em alguns setores do mundo acadêmico.

Vale ainda considerar duas principais limitações deste artigo. A primeira delas é reconhecer que a análise se restringiu apenas aos últimos dois anos (2015 e 2016) e aos 
trabalhos desenvolvidos exclusivamente em uma universidade do Brasil, ficando os programas de pós-graduação em direito de outras universidades brasileiras fora da análise. Nesse sentido, apresenta-se a oportunidade de ampliar o estudo, incluindo outros programas de pós-graduação na análise realizada. É possível que existam iniciativas diferenciadas e isoladas em relação às fontes de informação das pesquisas em direito no Brasil.

A outra limitação deste trabalho é o caráter subjetivo relacionado à avaliação dos artigos, segundos os critérios extraídos de Gonçalves (2011), especialmente na classificação segundo as fontes de informação. De fato, a heterogeneidade das abordagens dos artigos não permitiu realizar, em alguns casos, uma classificação extremamente precisa, de modo houvesse alguma margem de interpretação por parte dos pesquisadores para realizar a classificação.

\section{Referências Bibliográficas}

ADEODATO, J. M. Bases para uma metodologia da pesquisa em direito. Revista CEJ (Brasília), Brasília, v. 7, p. 143-150, 1999.

APPOLINÁRIO, F. Dicionário de metodologia científica: um guia para a produção do conhecimento científico. São Paulo, Atlas, 2009.

BASTOS, A. W. (1991) Pesquisa Jurídica no Brasil: Diagnóstico e Perspectivas. Sequência, vol. 12, nº 23. UFSC, Florianópolis, SC.

BRAGA, M. M. S; OLIVEIRA, R. M. de. A produção bibliográfica em coautoria nos grupos de pesquisa em direito. In: BEVILACQUA, A. V.; PINTO, F. C. de S. Direito, educação, epistemologias, metodologias do conhecimento e pesquisa jurídica I. Florianópolis:

CONPEDI, 2016. p. 54-72.

CERVO, A. L.; BERVIAN, P. A. Metodologia científica: para uso dos estudantes universitários. 3. ed. São Paulo: McGraw-Hill do Brasil, 1983.

CRUZ, F. B. da. A efetividade da Constituição Federal de 1988 quanto à delimitação do poder de edição de medidas provisórias. 2016. 197 f. Tese (Doutorado) - Pós-graduação em Direito, Universidade de São Paulo, São Paulo, 2016.

FRAGALE FILHO, Roberto. Panorama atual da pesquisa em direito no Brasil. Cadernos Direito GV, v. 5, p. 21-31, 2008.

FRAGALE FILHO, R.; NORONHA, R. (Org.). Pesquisa empírica em direito no Brasil: o estado da arte a partir da plataforma lattes e dos encontros do CONPEDI. In: OLIVEIRA, Fabiana Luci de. Justiça em foco: estudos empíricos. Rio de Janeiro: FGV, 2012. p. 97-144. 
FRAGALE FILHO, R.; VERONESE, A. K. A pesquisa em Direito: diagnóstico e perspectivas. RBPG. Revista Brasileira de Pós-Graduação, Brasília (DF), v. 2, p. 53-70, 2004.

GIL, A. C. Como elaborar projetos de pesquisa. 4. ed. São Paulo: Atlas, 2010.

GONSALVES, E. P. Conversas sobre iniciação à pesquisa científica. 3. ed. Campinas: Alínea, 2003.

GUIMARÃES, J. Uma fotografia da pós-graduação. Jornal da USP. São Paulo, p. 12-13. 08 abr. 2007.

GUSTIN, M. B. de S. et al. Pesquisa quantitativa na produção de conhecimento jurídico. Rev. Fac. Direito UFMG, Belo Horizonte, n. 60, p. 291-316, jun/2012.

JORNAL DA USP. Uma fotografia da pós-graduação, São Paulo, 02 abr. 2007. Cultura, p. 1213. Disponível em: <http://www.usp.br/jorusp/arquivo/2007/jusp796/pag13.htm>. Acesso em: 16 mar. 2017.

KUNZ, I. Dinâmica de produção de conhecimento na área de direito no Brasil. 2011. 245 f. Tese (Doutorado) - DPCT/IG/UNICAMP, Campinas, 2011.

MARTINS, G. de A.; THEÓPHILO, C. R. Metodologia da investigação científica para ciências sociais aplicadas. São Paulo: Atlas, 2007.

MATTOS, P. T. L.; PEREIRA NETO, C. M. S. Legal Research in Brazil: Traps and Alternatives to Legal Formalism. Revista Jurídica Universidad de Puerto Rico, v. 77, p. 445458, 2008.

NERI, M. C. Apresentação. In: Anais do I ENCONTRO DE PESQUISA EMPÍRICA EM DIREITO, Rio de Janeiro: Ipea, 2011.p. 7 - 9.

NOBRE, M. Apontamentos sobre a pesquisa em direito no Brasil. Novos Estudos. CEBRAP, São Paulo, v. 66, p. 145-154, 2003.

OLIVEIRA, F. L. de (Org.). O sistema de justiça brasileiro sob olhares empíricos. In: OLIVEIRA, F. L. de. Justiça em foco: estudos empíricos. Rio de Janeiro: FGV, 2012. p. 07-12.

SÁ-SILVA, J. R. et al. Pesquisa documental: pistas teóricas e metodológicas. Revista Brasileira de História \& Ciências Sociais, Curitiba, p. 1-15, jul. 2009. 